\title{
Liver stiffness measurement predicts the difficulty of Kasai procedure in biliary atresia: a single center retrospective analysis of 199 patients
}

Qiulong Shen, Yajun Chen * (D), Chunhui Peng, Wenbo Pang, Zengmeng Wang, Dongyang Wu, Kai Wang and Xinjie Huang

\begin{abstract}
Background: Kasai procedure is the standard initial treatment of infants with biliary atresia. The key to perform a successful surgery is to accurately remove the fibrous portal plate near the liver hilum. Yet how to estimate surgical difficulty pre-operatively remains unclear. This study aims to design an algorithm that predicts the difficulty of Kasai procedure using liver stiffness measurement (LSM).

Methods: One hundred ninety-nine patients were included from April 2012 to December 2016. The patients were all surgically diagnosed with biliary atresia. Group A comprised of patients with porta hepatis retraction (the angle between the plane of the fibrous porta plate and the plane of the medial liver closest to the plate was equal to or smaller than $90^{\circ}$ ), group B comprised of patients without porta hepatis retraction (the angle between the plane of the fibrous porta plate and the plane of the medial liver closest to the plate was greater than $90^{\circ}$ ). Liver function measurements and LSM were measured for all patients within three days before surgery.

Results: Our study included 19 cases in group A ( 9 males, 10 females) and 180 cases in group B (87 males, 93 females). LSM had statistical differences between the two groups, 28.10(14.90) kPa VS 10.89(7.10) $\mathrm{kPa}, P=0.000$. There was a significant relationship between LSM and operative age, TBA, AST, GGT $(P=0.000,0.003,0.003,0.012$, correlation coefficient $=0.323,0.213,0.207,0.179$ ). The AUROC of LSM was 0.919 . When the cutoff value was 15.15 $\mathrm{kPa}(O R=3.989 ; P=0.000)$, the sensitivity, specificity, $P P V, N P V$ and diagnostic accuracy were $0.947,0.750,0.285,0.992$ and 0.768 , respectively. When the value was $23.75 \mathrm{kPa}(O R=3.483 ; P=0.000)$, the sensitivity, specificity, PPV, NPV and diagnostic accuracy were $0.631,0.950,0.571,0.960$ and 0.919 , respectively.
\end{abstract}

Conclusions: LSM can be used to predict the difficulty in dissecting fibrous portal plate, and in turn, the difficulty of Kasai procedure. LSM > $23.75 \mathrm{kPa}$ suggests a more complicated surgery.

Keywords: Biliary atresia, Fibrous portal plate, Liver stiffness measurement, Kasai procedure

\footnotetext{
* Correspondence: chenyajun@bch.com.cn

Department of General Surgery, Beijing Children's Hospital, Capital Medical University, National Center for Children's Health, No.56 Nanlishi St, Xicheng District, Beijing 100045, China
}

(c) The Author(s). 2019 Open Access This article is distributed under the terms of the Creative Commons Attribution 4.0 International License (http://creativecommons.org/licenses/by/4.0/), which permits unrestricted use, distribution, and reproduction in any medium, provided you give appropriate credit to the original author(s) and the source, provide a link to the Creative Commons license, and indicate if changes were made. The Creative Commons Public Domain Dedication waiver (http://creativecommons.org/publicdomain/zero/1.0/) applies to the data made available in this article, unless otherwise stated. 


\section{Background}

Biliary atresia (BA) is an unique pediatric liver disease characterized by progressive inflammatory obliterative cholangiopathy. The Kasai procedure, introduced by Kasai from Japan, is the standard initial operation for treatment of infants with BA. The procedure aims to reconstruct biliary flow from the liver to the intestine. The adequate level of transection of the fibrous portal plate near the hilum of the liver is one of the most important steps, which is also the most difficult part of the operation. The adequate transection level of the fibrous portal plate plays a vital role in the early clearance of jaundice [1]. But there is no gold standard or descriptive articles that evaluate the difficulty of portal plate dissection. Surgical observation of our center shows that the porta hepatis retraction may affect the transection level owing to exposure difficulty. The porta hepatis retraction is more obvious in severe cirrhosis BA. LSM is a non-invasive and quantitative index that measures the degree of liver fibrosis. Therefore, the purpose of this study is to evaluate the porta hepatis retraction by preoperative non-invasive LSM examination, to assist in predicting the difficulty of the Kasai procedure.

\section{Methods}

\section{Patients}

Two hundred ninety-nine patients who were admitted to the General Surgery ward of Beijing Children's Hospital during April 2012 to December 2016 underwent retrospective analysis. We selected the patients based on the following: 1. Diagnosed as biliary atresia during surgery, and also received Kasai surgery 2. Liver function measurements and LSM were obtained within 3 days before surgery. Liver function measurements concluded the alkaline phosphatase (ALP), alanine aminotransferase (ALT), aspartate aminotransferase (AST), total bilirubin (TBIL), direct bilirubin (DBIL), total bile acid (TBA) and r-glutamyl transferase (GGT). Thirty patients did not have pre-surgical LSM and were excluded from this study.

\section{Grouping method}

We divided the patients into two groups based on surgical observation that was recorded at the time of surgery. Group A comprised of patients with porta hepatis retraction (the angle between the plane of the fibrous porta plate and the plane of the medial liver closest to the plate was equal to or smaller than $90^{\circ}$ ), group B comprised of patients without porta hepatis retraction (the angle between the plane of the fibrous porta plate and the plane of the medial liver closest to the plate was greater than $90^{\circ}$ ).

\section{LSM}

Fibroscan (Echosens, France) was used to assess liver stiffness, and an experienced operator was responsible for obtaining the LSM. A probe (size S) was placed vertically on the skin surface between the right lower ribs. Ten values were then obtained avoiding major vessels. A median value calculated by the Statistics Analyze System was chosen as the final value, and the interquartile median ratio was less than 0.3 .

\section{Statistical methods}

The data were analyzed using the SPSS 19.0 statistical software. Two independent sample t-test and rank sum test were used to analyze the difference in the data between the two groups. Spearman correlation coefficient analysis was also used for data analysis. The receive operating characteristic curve (ROC curve) was used to determine the cutoff values. Logistic regression was used to assess the odds ratio $(\mathrm{OR})$ and $95 \%$ confidence interval $(\mathrm{CI})$. A $P$ value $<0.05$ was considered statistically significant.

\section{Results}

\section{General characteristics}

One hundred ninety nine children $(96$ males and 103 females) with BA were included in this retrospective analysis. Among them, 19 cases were in group A(9 males, 10 females $)$ and 180 cases were in group B $(87$ males, 93 females). Cases of group $\mathrm{A}(n=19)$ had higher LSM, TBA, and ALT values than group $\mathrm{B}(n=180 ; P=0.000$, 0.012, 0.030, respectively; Table 1, Fig. 1 ).

\section{Relationships between LSM and others}

From the 199 cases, there was no relationship between LSM and ALP $(P=0.177)$, LSM and ALT $(P=0.058)$, LSM and TBIL $(P=0.188)$, or LSM and DBIL $(P=$ $0.173)$. There was a significant relationship between LSM and operative age $(P=0.000$, correlation coefficient $=0.323)$, LSM and AST $(P=0.003$, correlation coefficient $=0.207)$, LSM and GGT $(P=0.012$, correlation coefficient $=0.179)$, LSM and TBA $(P=0.003$, correlation

Table 1 General characteristics of two groups

\begin{tabular}{llll}
\hline & Group $\mathrm{A}(n=19)$ & Group $\mathrm{B}(n=180)$ & $P$ value \\
\hline $\mathrm{LSM}$, median (IQR), kPa & $28.10(14.90)$ & $10.89(7.10)$ & 0.000 \\
$\mathrm{TBIL}, \mathrm{X} \pm \mathrm{S}, \mathrm{umol} / \mathrm{I}$ & $191.92 \pm 69.63$ & $188.83 \pm 52.42$ & 0.853 \\
$\mathrm{DBIL}, \mathrm{X} \pm \mathrm{S}, \mathrm{umol} / \mathrm{I}$ & $95.75 \pm 35.09$ & $97.52 \pm 25.78$ & 0.833 \\
$\mathrm{TBA}, \mathrm{X} \pm \mathrm{S}, \mathrm{umol} / \mathrm{I}$ & $156.53 \pm 53.73$ & $121.64 \pm 38.44$ & 0.012 \\
$\mathrm{GGT}$, median (IQR), U/L & $401.00(729.50)$ & $590.00(678.03)$ & 0.459 \\
$\mathrm{ALT}$, median (IQR), U/L & $174.40(219.80)$ & $136.60(121.05)$ & 0.030 \\
AST, median (IQR), U/L & $331.40(144.80)$ & $261.75(155.98)$ & 0.057 \\
ALP, median (IQR), U/L & $582.00(387.00)$ & $568.00(317.00)$ & 0.724 \\
Operative Age, X $\pm \mathrm{S}, \mathrm{d}$ & $82.47 \pm 17.25$ & $74.03 \pm 21.01$ & 0.059 \\
\hline
\end{tabular}

LSM liver stiffness measurement; TBIL total bilirubin; DBIL direct bilirubin; TBA total bile acid; GGT Gamma-glutamyltransferase; $A L T$ alanine aminotransferase; AST aspartate aminotransferase; ALP alkaline phosphatase 

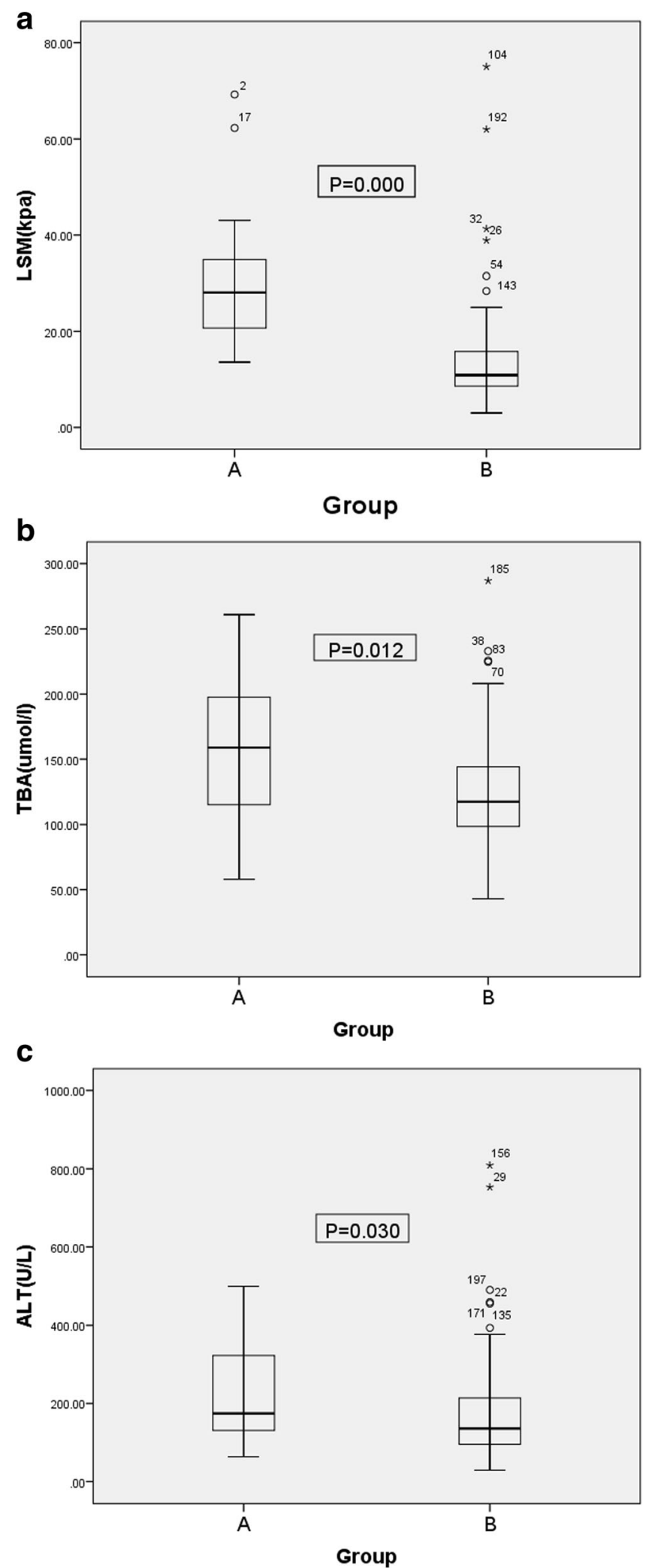

Fig. 1 Box Plot of $\operatorname{LSM}(\mathbf{a}), \operatorname{TBA}(\mathbf{b}), \operatorname{ALT}(\mathbf{c})$ 
coefficient $=0.213)$ in the 199 cases; however, the correlation coefficients were not high.

\section{Cut-off value for the two groups}

The ROC curves of LSM, biochemical markers and the operative age were analyzed. The results of ROC analysis are shown in Table 2. $P$ values of LSM, TBA, ALT and operative age revealed statistical significance $(P=0.000$, $0.005,0.031$ and 0.038 , respectively). The AUROC of LSM, TBA, ALT, and the operative age were 0.919, 0.698, 0.651and 0.645, respectively (Fig. 2). The AUROC of AST, TBIL, DBIL, and GGT were 0.633, 0.499, 0.479 and 0.444 , respectively $(P=0.057,0.990,0.763$ and 0.425 , respectively).

\section{Efficiency evaluation of LSM in predicting the difficulty of the Kasai procedure}

Only the AUROC of LSM was more than 0.7. Using the Jordan index, the optimal cut-off value of LSM was $15.15 \mathrm{kpa}$, with a sensitivity of 0.947 and a specificity of 0.739 . When the specificity was increased to 0.90 , the cutoff value was $20.9 \mathrm{kPa}$ and the sensitivity was low. When the specificity was increased to 0.95 , the cut-off value was $23.75 \mathrm{kPa}$ and the sensitivity was lower (Table 3 ).

A LSM $>15.15 \mathrm{kPa}$, LSM $>20.90 \mathrm{kPa}$ and LSM $>23.75$ $\mathrm{kPa}$ were predictive of the difficulty of the Kasai procedure in univariate logistic regression analyses $(\mathrm{OR}=3.989$, 3.290 and 3.483; $P=0.000,0.000$ and 0.000 , respectively). The positive and negative predictive values (PPV and NPV) of an LSM value cut-off $>15.15 \mathrm{kPa}, 20.90 \mathrm{kPa}$ and $23.75 \mathrm{kPa}$ were $0.285,0.451,0.571$ and $0.992,0.964,0.960$, respectively. The diagnostic accuracies were $0.768,0.889$ and 0.919 , respectively (Table 3 ).

\section{Discussion}

$\mathrm{BA}$ is a unique pediatric liver disease characterized by progressive inflammatory obliterative cholangiopathy. If left untreated, fibrosclerosing obliteration progresses in both intrahepatic and extrahepatic bile ducts, which

Table 2 ROC Analysis Results of LSM, Biochemical Markers and the Operative Age

\begin{tabular}{llllll}
\hline & AUROC & P value & Cutoff value & sensitivity & specificity \\
\hline LSM, kPa & 0.919 & 0.000 & 15.15 & 0.947 & 0.739 \\
Operative age, d & 0.645 & 0.038 & 87.0 & 0.474 & 0.790 \\
ALT, U/L & 0.651 & 0.031 & 109.45 & 0.947 & 0.313 \\
TBA, umol/I & 0.698 & 0.005 & 155.40 & 0.579 & 0.824 \\
ALP, U/L & 0.525 & 0.724 & - & - & - \\
AST, U/L & 0.633 & 0.057 & - & - & - \\
GGT, U/L & 0.444 & 0.425 & - & - & - \\
TBIL, umol/I & 0.499 & 0.990 & - & - & - \\
DBIL, umol/l & 0.479 & 0.763 & - & - & - \\
\hline
\end{tabular}

inevitably leads to liver cirrhosis [2]. The incidence of BA in Asia is reported to be as high as approximately 1 in 5000 live births [3].

Kasai procedure is a standard surgical treatment for BA, which has been widely carried out. The adequate level of transection of the fibrous portal plate is one of the most important steps in the Kasai procedure, which is also the most difficult part of the operation. The native liver survival (NLS) rate is clearly different in different centers [4-7].At present, most studies showed that early clearance of jaundice after Kasai procedure is an important factor for good prognosis [4, 7]. The adequate level of transection of the fibrous portal plate plays a key role in the early clearance of jaundice [1]. The more severe the degree of liver cirrhosis, the more difficult to anatomize the fibrous plate will be, which may lead to the transection level not exact enough. It can affect bile drainage and ultimately the clearance of jaundice.

There is no literature that describes exactly how to define the difficulty of dissecting the fibrous portal plate. A recent study has demonstrated that removing a part of the medial liver closest to the fibrous porta plate aids in exposure of the porta hepatis and provides the surgeon with a better surgical field [8]. Similar to the study, our center has found that more severe liver cirrhosis presents with more severe edema, which presents as porta hepatis retraction. This causes difficulty when exposing the fibrous portal plate during surgery and blocks the surgical field to varying degrees.

The Kasai procedure has been carried out in our center for more than ten years. The five-year NLS rate is $58 \%$ [9]. Through observation, we found that the more severe the cirrhosis, the more obvious the vascular proliferation around the fibrous portal plate, which led to easy bleeding during the dissection. If hemostasis is done by electrocoagulation, it will easily damage the fine ductules in the porta hepatis and this will affect prognosis. At the point of surgery, we had no means to measure vascular proliferation and this remains an ongoing challenge. A method to measure vascular proliferation would provide more insight to the degree of surgical difficulty.

The gold standard to judge the degree of liver fibrosis is liver biopsy, but it is an invasive examination. Before the operation, the degree of liver fibrosis of BA is judged only by clinical presentation, for example, operative age or blood test. But there is no uniform standard for the specific cut-off value, and there is still controversy surrounding the correlation between the operative age and the prognosis. A multivariable analysis including 244 case in a single center of China showed that the low 5 year NLS rate of children with BA was associated with the operative age over 90 days [10]. Moreover, other studies suggested that when the operative age was over 60 days, postoperative NLS rate declined and liver 


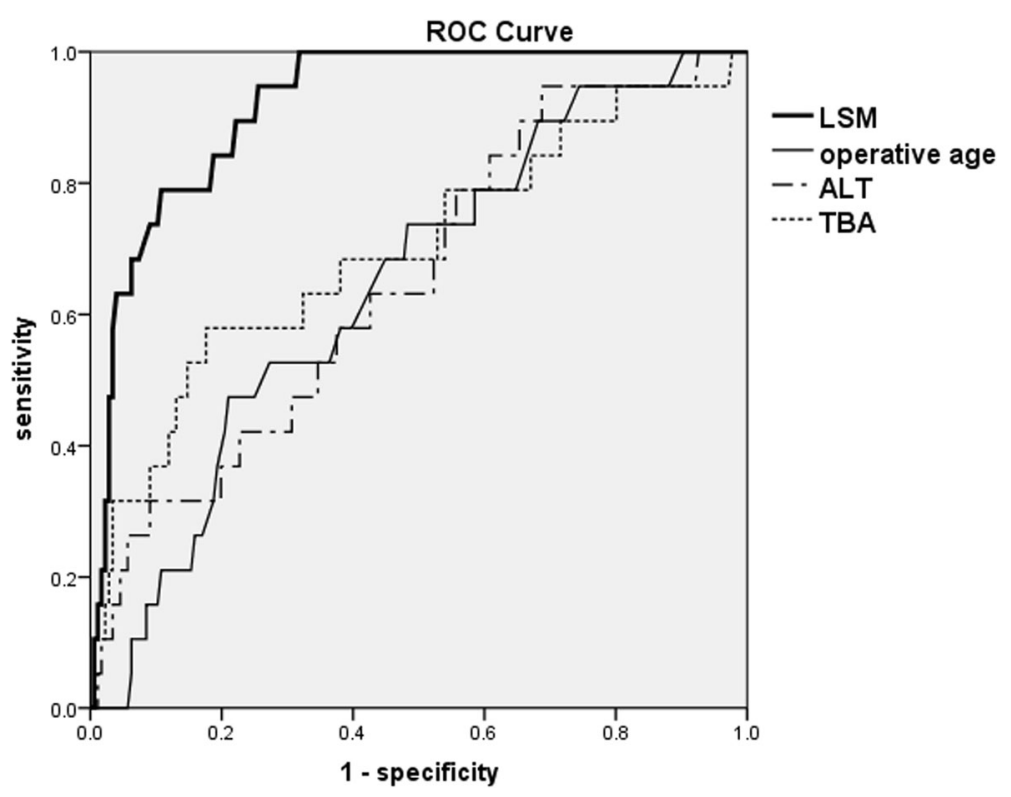

Fig. 2 ROC curve of LSM, Operative age, ALT and TBA

transplantation rate increased [11, 12]. However, several studies suggested that there is no correlation between the operative age and postoperative NLS [13, 14]. Studies have shown that 5 years and 10 years NLS rate of the children whose operative ages were over 100 days can reach 40 and $45 \%$ [15]. In this study, there was no correlation between the operative age in the two groups. Therefore, we speculated that the operative age might not be an effective index for judging severe cirrhosis and is not a factor for the difficulty of the surgical procedure.

LSM is a noninvasive technique which is used to assess the degree of liver fibrosis. The basic principle of LSM involves a one-dimensional transient elastographic wave, which has a distinguishable traveling speed in different media, and can be translated into various degrees of fibrosis. When the liver is hard, the transient elastographic wave travels faster, resulting in a higher LSM value $(\mathrm{kPa})$. It has the characteristics of being noninvasive, accurate, rapid and repeatable. It has been widely used in the determination of liver fibrosis in adults [16-19], but the application of LSM in children is markedly fewer than in adults. It can be used to evaluate the degree of liver fibrosis in different liver diseases, auxiliary diagnosis of portal hypertension and upper gastrointestinal tract varices [20,21]. The normal LSM of children is about $5.0 \mathrm{kPa}$, which is consistent with adults
$[22,23]$. LSM is a routine procedure at our hospital, and all patients with BA are sent for LSM before and after surgery, as well as during follow ups. The preliminary result of our center shows that LSM can be used to measure the degree of liver fibrosis in children with BA, and the cut-off value of liver cirrhosis is $15.15 \mathrm{kPa}$ [24].

In this study, 199 cases of BA were reviewed and analyzed by ROC curve analysis. The cut-off value of LSM used to distinguish the two groups was $15.15 \mathrm{kpa}$, and its sensitivity was high and the specificity was relatively low. When the cut-off value of LSM is $23.75 \mathrm{kPa}$, the sensitivity is relatively low and the specificity is significantly higher, which is consistent with the clinical observation of our center. According to our center's early findings, BA children with an LSM less than $15.15 \mathrm{kPa}$ did not reach liver cirrhosis [24]. Combined with the results of this study, when LSM was less than $15.15 \mathrm{kPa}$, there was little possibility of porta hepatis retraction. If LSM was greater than $23.75 \mathrm{kPa}$ before operation, the possibility of porta hepatis retraction is high.

Studies have shown that LSM is influenced by aminotransferase, bilirubin and other factors [25-27]. In this study, ALP, ALT, AST, TBIL, DBIL, TBA and GGT were compared in the two groups. LSM was positively

Table 3 Efficiency Evaluation of LSM in Assessing the Difficulty of the Fibrous Plate Dissection of BA

\begin{tabular}{llllllll}
\hline & OR(95\%Cl) & P value & NPV & PPV & Sensitivity & specificity & Diagnostic accuracy \\
\hline LSM > 15.15kpa versus $\leq 15.15 \mathrm{kpa}$ & $3.989(7.009-416.015)$ & 0.000 & 0.992 & 0.285 & 0.947 & 0.75 & 0.768 \\
$\mathrm{LSM}>$ 20.9kpa versus $\leq 20.9 \mathrm{kpa}$ & $3.290(8.614-83.673)$ & 0.000 & 0.964 & 0.451 & 0.736 & 0.905 & 0.889 \\
$\mathrm{LSM}>23.75 \mathrm{kpa}$ versus $\leq 23.75 \mathrm{kpa}$ & $3.483(10.333-102.674)$ & 0.000 & 0.960 & 0.571 & 0.631 & 0.950 & 0.919 \\
\hline
\end{tabular}


correlated with AST, GGT and TBA. But the correlation coefficient is not high.

There is no difference in the prognosis between BA with and without a Kasai procedure prior to liver transplantation $[28,29]$. Although the incidence of complications increases, the Kasai procedure with effective bile drainage could significantly improve the liver transplantation-free survival [30], reduce the high demand for liver donors, and also effectively reduce the difficulty of liver transplantation. The results showed that when LSM reached a certain degree, porta hepatis retraction was notably present, portal plate dissection was relatively difficult, and the need to have the operation performed by a team with rich experience in the Kasai procedure was necessary. This was to ensure that bile drainage successfully occurred after the operation and to achieve long-term liver transplantationfree survival. Therefore, if conditions permit, BA children with LSM over $23.75 \mathrm{kPa}$ should be transferred to a large clinical center with vast experience with the Kasai procedure for treatment, allowing for a greater chance of surgical success, and thus avoiding a meaningless operation and reducing the financial burden of the family.

\section{Conclusion}

LSM can be used to predict the difficulty in dissecting fibrous portal plate, and in turn the difficulty of Kasai procedure. LSM $>23.75 \mathrm{kPa}$ suggests a more complicated surgery.

\section{Abbreviations \\ ALP: Alkaline phosphatase; ALT: Alanine aminotransferase; AST: Aspartate aminotransferase; AUROC: Area under the receiver operating characteristic; BA: Biliary atresia; DBIL: Direct bilirubin; GGT: R-glutamyl transferase; LSM: Liver stiffness measurement; NPV: Negative predictive value; PPV: Positive predictive value; TBA: Total bile acid; TBIL: Total bilirubin}

\section{Acknowledgements}

The authors thank the entire staff of the Department of General Surgery, Beijing Children's Hospital, Capital Medical University, National Center for Children's Health.

\section{Authors' contributions}

QLS and YJC conceived and designed the study, helped with the data collection, and drafted the initial manuscript. CHP, WBP, ZMW, DYW, KW and $\mathrm{XJH}$ helped with the data collection. All authors have read and approved the manuscript, and ensure that this is the case.

\section{Funding}

This research receive financial support from Beijing Municipal Administration of Hospitals Clinical Medicine Development of Special Funding Support, code: XMLX201603.

\section{Availability of data and materials}

The data is available from the corresponding author on reasonable request.

\section{Ethics approval and consent to participate}

The work has been approved by the Ethical Committees of Beijing Children's Hospital(2019 k61). Written informed consent was obtained from the parents.

\section{Consent for publication}

Not applicable.

\section{Competing interests}

The authors declare that they have no competing interest.
Received: 7 August 2019 Accepted: 21 November 2019

Published online: 29 November 2019

\section{References}

1. de Carvalho NMN, Torres SM, Cavalcante JCB, et al.

Hepatoportoenterostomy surgery technique. J Pediatr Surg. 2019;54(8): 1715-8. https://doi.org/10.1016/j.jpedsurg.2018.10.041.

2. Hartley UL, Davenport M, Kelly DA. Biliary atresia. Lancet. 2009;374:1704-13.

3. Hsiao $\mathrm{CH}$, Chang $\mathrm{MH}$, Chen $\mathrm{HL}$, et al. Universal screening for biliary atresia using an infant stool color card in Taiwan. Hepatol. 2008:47:1233-40. https://doi.org/10.1002/hep.22182.

4. Bjørnland K, Hinna M, Aksnes G, et al. Outcome for biliary atresia patients treated at a low-volume Centre. Scand J Gastroenterol. 2018:53(4):471-4. https://doi.org/10.1080/00365521.2018.1439097.

5. De Maayer T, Lala SG, Loveland J, et al. Outcomes of Kasai hepatoportoenterostomy in children with biliary atresia in Johannesburg. S Afr Med J. 2017;107(10):12131. 29183423.

6. Pakarinen MP, Johansen LS, Svensson JF, et al. Outcomes of biliary atresia in the Nordic countries-a multicenter study of 158 patients during 2005-2016. J Pediatr Surg. 2018;53(8):1509-15. https://doi.org/10. 1016/j.jpedsurg.2017.08.048.

7. Redkar R, Karkera PJ, Raj V, et al. Outcome of biliary atresia after Kasai's Portoenterostomy: a 15-year experience. Indian Pediatr. 2017;54(4):291-4. 28159941.

8. Bing L, Wei-Bing C, Xia H, et al. Modifications to expose porta hepatis for laparoscopic portoenterostomy easier in biliary atresia. J Surg Reg. 2019;233: 368-75. https://doi.org/10.1016/j.jss.2018.08.013.

9. Wang $Z$, Chen $Y$, Peng $C$, et al. Five-year native liver survival analysis in biliary atresia from a single large Chinese center: the death/liver transplantation hazard change and the importance of rapid early clearance of jaundice. J Pediatr Surg. 2019;54(8):1680-5. https://doi.org/10.1016/j. jpedsurg.2018.09.025.

10. Qiao G, Li L, Cheng W, et al. Conditional probability of survival in patients with biliary atresia after Kasai portoenterostomy: a Chinese populationbased study. J Pediatr Surg. 2015;50(8):1310-5. https://doi.org/10.1016/j. jpedsurg.2015.03.062.

11. deVries W, de Langen ZJ, Groen H, et al. Biliary atresia in the Netherlands: Outcome of patients diagnosed between 1987 and 2008. J Pediatr. 2012; 160(4):638-44. https://doi.org/10.1016/j.jpeds.2011.09.061.

12. Rhu J, Jung SM, Choe YH, et al. PELD score and age as a prognostic index of biliary atresia patients undergoing Kasai portoenterostomy. Pediatr Surg Int. 2012;28(4):385-91. https://doi.org/10.1007/s00383-012-3060-3.

13. Chung PH, Wong KK, Tam PK. Predictors for failure after Kasai operation. J Pediatr Surg. 2015;50(2):293-6. https://doi.org/10.1016/j.jpedsurg.2014.11.015.

14. Muthukanagarajan SJ, Karnan I, Srinivasan P, et al. Diagnostic and prognostic significance of various histopathological features in extrahepatic biliary atresia. J Clin Diagn Res. 2016;10(6):EC23-EC7. https://doi.org/10.7860/JCDR/ 2016/19252.8035

15. Davenport M, Puricelli V, Farrant $P$, et al. The outcome of the older $(\geq 100$ days) infant with biliary atresia. J Pediatr Surg. 2004:39(4):575-81. 15065031.

16. Garg H, Aggarwal S, Shalimar, et al. Utility of transient elastography (fibroscan) and impact of bariatric surgery on nonalcoholic fatty liver disease (NAFLD) in morbidly obese patients. Surg Obes Relat Dis. 2018;14(1): 81-91. https://doi.org/10.1016/j.soard.2017.09.005.

17. Huang Z, Huang J, Zhou T, et al. Prognostic value of liver stiffness measurement for the liver-related surgical outcomes of patients under hepatic resection: a meta-analysis. PLoS One. 2018;13(1):e0190512. https:// doi.org/10.1371/journal.pone.0190512.

18. Kamarajah SK, Chan WK, Nik Mustapha NR, et al. Repeated liver stiffness measurement compared with paired liver biopsy in patients with nonalcoholic fatty liver disease. Hepatol Int. 2018;12(1):44-55. https://doi.org/10. 1007/s12072-018-9843-4.

19. Tag-Adeen M, Alsenbesy M, Ghweil AA, et al. Liver stiffness measurement and spleen diameter as predictors for the presence of esophageal varices in chronic hepatitis C patients. Medicine (Baltimore). 2017:96(46):e8621. https:// doi.org/10.1097/MD.0000000000008621

20. Cassinotto C, Charrie A, Mouries A, et al. Liver and spleen elastography using supersonic shear imaging for the non-invasive diagnosis of cirrhosis severity and oesophageal varices. Dig Liver Dis. 2015;47(8):695-701. https:// doi.org/10.1016/j.dld.2015.04.008. 
21. Elkrief $L$, Ronot $M$, Andrade $F$, et al. Non-invasive evaluation of portal hypertension using shear-wave elastography: analysis of two algorithms combining liver and spleen stiffness in 191 patients with cirrhosis. Aliment Pharmacol Ther. 2018;47(5):621-30. https://doi.org/10.1111/apt.14488.

22. Ferraioli $G$, Lissandrin R, Zicchetti $M$, et al. Assessment of liver stiffness with transient elastography by using $\mathrm{S}$ and $\mathrm{M}$ probes in healthy children. Eur J Pediatr. 2012;171(9):1415. https://doi.org/10.1007/s00431-012-1777-6.

23. Honsawek S, Chayanupatkul M, Chongsrisawat V, et al. Increased osteopontin and liver stiffness measurement by transient elastography in biliary atresia. World J Gastroenterol 2010; 16(43): 5467-5473. PMID: 21086566. PMCID: PMC2988241

24. Shen QL, Chen YJ, Wang ZM, et al. Assessment of liver fibrosis by Fibroscan as compared to liver biopsy in biliary atresia. World J Gastroenterol. 2015; 21(22):6931-6. https://doi.org/10.3748/wjg.v21.i22.6931.

25. Chen XB, Zhu X, Chen LY, et al. Accuracy of FibroScan for the diagnosis of liver fibrosis influenced by serum alanine aminotransferase levels in patients with chronic hepatitis B. Zhonghua Gan Zang Bing Za Zhi. 2011;19(4):28690. https://doi.org/10.3760/cma.j.jssn.1007-3418.2011.04.013.

26. Harata M, Hashimoto S, Kawabe N, et al. Liver stiffness in extrahepatic cholestasis correlates positively with bilirubin and negatively with alanine aminotransferase. Hepatol Res. 2011;41(5):423-9. https://doi.org/10.1111/j. 1872-034X.2011.00797.X.

27. Shan $\mathrm{R}$, Yin $\mathrm{H}$, Yang $\mathrm{W}$, et al. Influencing factors of transient elastography in detecting liver stiffness. Exp Ther Med. 2016;12(4):2302-6. https://doi.org/10. 3892/etm.2016.3617.

28. Safwan M, Ramachandran P, Reddy MS, et al. Living donor liver transplantation for biliary atresia - an Indian experience. Pediatr Transplant. 2016;20(8):1045-50. https://doi.org/10.1111/petr.12749.

29. Wang P, Xun P, He K, et al. Comparison of liver transplantation outcomes in biliary atresia patients with and without prior portoenterostomy: a meta-analysis. Dig Liver Dis. 2016;48(4):347-52. https://doi.org/10.1016/.jdld.2015.11.021.

30. Li S, Ma N, Meng X, et al. The effects of Kasai procedure on living donor liver transplantation for children with biliary atresia. J Pediatr Surg. 2019; 54(7):1436-9. https://doi.org/10.1016/j.jpedsurg.2018.07.022.

\section{Publisher's Note}

Springer Nature remains neutral with regard to jurisdictional claims in published maps and institutional affiliations.

Ready to submit your research? Choose BMC and benefit from:

- fast, convenient online submission

- thorough peer review by experienced researchers in your field

- rapid publication on acceptance

- support for research data, including large and complex data types

- gold Open Access which fosters wider collaboration and increased citations

- maximum visibility for your research: over $100 \mathrm{M}$ website views per year

At $\mathrm{BMC}$, research is always in progress.

Learn more biomedcentral.com/submissions 